\title{
AVALIAÇÃo DOS PARÂMETROS DE UM BIODIGESTOR PARA TRATAR LIXIVIADOS DE RESÍDUOS SÓLIDOS URBANOS
}

\author{
Rodrigo César de Vasconcelos dos SANTOS ${ }^{1}$; Rosângela Francisca de Paula Vitor \\ MARQUES ${ }^{2}$; Antônio Marciano da SILVA ${ }^{3}$; André Geraldo Cornélio RIBEIRO ${ }^{4}$; Lucas \\ Coelho VICTÓRIA ${ }^{5}$
}

\footnotetext{
${ }^{1}$ Engenheiro Ambiental e Sanitarista (UFLA). Doutorando em Recursos Hídricos Departamento de Engenharia, Universidade Federal de Lavras. E-mail: drigovasc@hotmail.com.

${ }^{2}$ Engenheira Florestal. Doutora em Recursos Hídricos em Sistemas Agrícolas (UFLA). Professora tempo integral - Mestrado em Sustentabilidade em Recursos Hídricos (UNINCOR) E-mail: roeflorestal@hotmail.com.

3 Engenheiro Agrônomo. Doutor em Engenharia Hidráulica e Saneamento. Universidade Federal de Lavras. E-mail: marciano@deg.ufla.br.

${ }^{4}$ Engenheiro Civil. Doutor em Engenharia Civil. Professor Adjunto do Departamento de Engenharia, setor de Engenharia Ambiental e Sanitária da Universidade Federal de Lavras. E-mail: andreribeiro@deg.ufla.br.

${ }^{5}$ Engenheiro Ambiental e Sanitarista (UFLA). E-mail: lucas.c.victoria@gmail.com.
}

Recebido em: 10/09/2017 - Aprovado em: 28/09/2017 - Disponibilizado em: 30/12/2017

Resumo: Os custos para a implantação de um aterro sanitário e, consequentemente um sistema de tratamento de chorume, são onerosos para municípios de pequeno porte. Sabendo-se do baixo custo de manutenção e simplicidade de operação de biodigestores, quando comparados a outros sistemas de tratamento, objetivou-se com esse trabalho, avaliar o potencial poluidor de diferentes composições de resíduos sólidos urbanos e o potencial de remoção de matéria orgânica e sólidos totais do chorume através de tratamento secundário utilizando biodigestores. Para a montagem do experimento, os resíduos foram pesados e misturados com diferentes porcentagens de matéria orgânica $(0,30$ e 60\%), rejeito e reciclável, seguindo uma ordem para um conjunto de três recipientes, que foram ligados a um biodigestor para o tratamento, denominados de Sistemas 1, 2 e 3. Os parâmetros avaliados foram: pH, Demanda Química de Oxigênio (DQO), Carga Orgânica Volumétrica (COV), alcalinidade, sólidos totais. O Sistema 3 foi o que apresentou melhor desempenho em relação aos parâmetros estudados, muito possivelmente em relação ao teor de matéria orgânica, corroborando com a legislação que preconiza o aterramento de $30 \%$ de matéria orgânica para aterro sanitário de pequeno porte. As características do lixiviado resíduo sólido digerido anaerobiamente indicaram que o teor médio de matéria orgânica e sólidos se apresentaram ainda de forma elevada. Os níveis de remoção de matéria orgânica também não foram satisfatórios conferindo uma maior eficiência para o Sistema 3 da ordem de $24 \%$. Esses resultados indicam que o efluente possui características inadequadas à disposição e/ao reuso, sendo necessária a adição de uma etapa de póstratamento para adequação do efluente.

Palavras-chave: Matéria Orgânica. Sólidos totais. Percolado. Digestão anaerobia. Eficiência de remoção.

\section{EVALUATION OF PROJECT PARAMETERS OF A LOW-LOAD ANAEROBIC REACTOR TREATING LEACHED SOLID WASTE FROM URBAN RESIDUES}

\begin{abstract}
The costs for the implementation of a landfill and, consequently, a slurry treatment system, are costly for small municipalities. Considering the low maintenance cost and simplicity of operation of biodigesters, when compared to other treatment systems, the objective of this study was to evaluate the pollutant potential of different compositions of urban solid waste and the potential for removal of organic matter and solids total slurry through secondary treatment using biodigesters. For the assembly of the experiment, the residues were weighed and mixed with different percentages of organic matter $(0,30$ and $60 \%$ ), reject and recyclable, following an order for a set of three containers, which were connected to a biodigester for the treatment, denominated Systems 1, 2 and 3. The evaluated parameters were: pH, Chemical Oxygen Demand (COD), Volumetric Organic Load (VOC), alkalinity, total solids. System 3 was the one that presented better performance in relation to the studied parameters, very possibly in relation to the organic matter content, corroborating with the legislation that recommends the grounding of $30 \%$ of organic matter for small landfill. The characteristics of the anaerobically digested solid residue leachate indicated that the average organic matter content and solids were still high. The levels of organic matter removal were also not satisfactory, giving a greater efficiency for System 3 of the order of $24 \%$. These results indicate that the effluent has inadequate characteristics at disposal and / or reuse, and the addition of a post-treatment step to adequacy of the effluent is necessary.
\end{abstract}

Keywords: Organic matter. Total solids. Percolated. Anaerobic digestion. Efficiency of removal. 


\section{INTRODUÇÃO}

Entre os desafios ambientais do país, a grande geração de resíduos sólidos urbanos (RSU) está entre os mais consideráveis e representativos. Problemas significativos foram observados, especialmente na última década, no tocante à diversificação e ao aumento no descarte de materiais produzidos pelas indústrias para suprir a demanda da população por bens manufaturados. A grande quantidade de resíduos gerada pelas atividades industriais, agrícolas, comerciais e domésticas tem sido considerada uma das maiores responsáveis pela poluição ambiental no Brasil e no mundo. Esse cenário aliado à má gestão praticada pelo poder público tem como consequência o surgimento de áreas clandestinas de deposição de resíduos, ocasionando a poluição do solo, da água e do ar, além da proliferação de vários vetores de doenças.

Desta forma, o esforço para encontrar soluções técnicas viáveis e ambientalmente corretas para disposição dos resíduos sólidos estudando as características desse material, é tema de vários trabalhos dos mais diversos pesquisadores como Ribeiro et al. (2013), Durmusoglu et al. (2006), Dixon \& Jones (2005) e Boscov \& Abreu (2000).

Com o intuito de solucionar essa problemática dos RSU, a Política Nacional de Resíduos Sólidos (PNRS), instituída por meio da Lei Federal $n^{\circ} 12.305 / 2010$, que preconiza a disposição final dos rejeitos em aterros sanitários, proibindo, a partir de agosto de 2014, a disposição de resíduos por parte dos municípios em vazadouros a céu aberto ("lixões"). No entanto, em julho de 2015, foi aprovada a lei $2289 / 2015$, que propõe a prorrogação do prazo para os municípios erradicarem os lixões, adequarem o gerenciamento dos RSU e adotarem disposição dos rejeitos em aterros sanitários, com prazos escalonados que variam entre os anos de 2018 a 2021, de acordo com o porte do município.

A digestão anaeróbia para o tratamento do chorume é muito importante no manejo dos resíduos. É um processo complexo e é influenciado por muitos fatores. Estes fatores incluem especificidade de águas residuais, tempo de detenção hidráulica, concentração orgânica afluente, taxa de carga orgânica, temperatura, $\mathrm{pH}$, exigências nutricionais, relação carbono nitrogênio (GAO et al., 2010; RASTOGI et al., 2008).

$\mathrm{O}$ pH é um parâmetro importante que afeta o crescimento dos microrganismos durante a fermentação anaeróbia. A faixa ideal de $\mathrm{pH}$ de um biodigestor varia de 6,8 a 7,2. Um valor aceitável de $\mathrm{pH}$ para a digestão anaeróbia parece girar entre 6,0 a 8,0 (GAO et al., 2010; KUNZ, 2010).

A quantidade de dióxido de carbono e ácidos graxos voláteis produzidos durante o 
processo anaeróbico afeta $\mathrm{o} \mathrm{pH}$ dentro do biodigestor. Para a fermentação anaeróbia ocorrer, normalmente, a concentração de ácidos graxos voláteis, principalmente, a de acetato, deve ser de 2000 mg.L $\mathrm{L}^{-1}$ (YADVIKA et al., 2004).

$\mathrm{O}$ controle da alcalinidade nos reatores anaeróbios é de suma importância por esta ser a responsável de tamponar os ácidos voláteis e assim manter o $\mathrm{pH}$ equilibrado (BARCELOS, 2009). Chernicharo (2007) afirma que o controle da alcalinidade é mais importante que o controle do $\mathrm{pH}$, por este variar em escala logarítmica, ou seja, um pequeno abaixamento de $\mathrm{pH}$ consumir uma grande quantidade de alcalinidade.

A digestão anaeróbia é uma técnica promissora, porém, não muito difundida devido à falta de configurações de sistemas de tratamento e, sobretudo, aos cuidados operacionais necessários com a partida e operação do sistema (REIS, 2012).

Nesta esfera, o grande desafio para a pesquisa é desenvolver estratégias para diminuir o potencial poluidor do chorume. Interesse crescente vem sendo dado para $o$ tratamento usando biodigestores, podendo ser uma alternativa bem interessante à utilização desses processos para o tratamento do chorume e assim diminuir o impacto ambiental causado por estas atividades.

Neste contexto, objetivou-se com esse trabalho avaliar o potencial poluidor de diferentes composições de resíduos sólidos urbanos e o potencial de remoção de matéria orgânica e sólidos do chorume por meio de tratamento secundário utilizando biodigestores.

\section{MATERIAL E MÉTODOS}

O experimento foi conduzido no Departamento de Engenharia da Universidade Federal de Lavras (UFLA), no município de Lavras - MG. A área situase nas coordenadas geográficas de $21^{\circ} 13^{\prime}$ de Latitude Sul e $44^{\circ} 58^{\prime}$ de Longitude Oeste e $909 \mathrm{~m}$ de altitude. Segundo a classificação de Koppen, o clima da região é Cwa, com temperatura média anual do ar de $19,4{ }^{\circ} \mathrm{C}$ e o total anual médio de precipitação de 1530 mm (BRASIL, 1992).

Foram utilizados recipientes com $1,0 \mathrm{~m}$ de comprimento e $0,52 \mathrm{~m}$ de diâmetro para abrigar as diferentes composições de resíduos. Os biodigestores foram confeccionados utilizando reservatórios de fibra de vidro com as dimensões de $0,4 \mathrm{~m}$ de altura, 0,5 $\mathrm{m}$ de diâmetro na base menor e $0,7 \mathrm{~m}$ de diâmetros na base maior.

Os resíduos sólidos urbanos foram coletados na Usina de Triagem e Compostagem, no município de Nazareno $\mathrm{MG}$, os quais foram segregados de acordo com as tipologias: rejeito, matéria orgânica e reciclável. 
Para o enchimento dos recipientes, primeiramente foram consideradas as densidades de resíduos compactados: 500 $\mathrm{kg} \cdot \mathrm{m}^{-1}$ de matéria orgânica; $300 \mathrm{~kg} \cdot \mathrm{m}^{-1}$ de rejeito e $300 \mathrm{~kg} \cdot \mathrm{m}^{-1}$ de recicláveis.

Os resíduos foram pesados e misturados com as porcentagens de matéria orgânica, rejeito e reciclável seguindo uma ordem para um conjunto de três recipientes. Um conjunto com apenas rejeito, outro com $60 \%$ de matéria orgânica, $20 \%$ de rejeito e $20 \%$ de reciclável de acordo com a caracterização gravimétrica realizada por Franco (2012) representando a realidade no sul de Minas Gerais e no terceiro e último conjunto, 30\% de matéria orgânica, 35\% de reciclável e $35 \%$ de rejeito. Os recipientes foram tampados evitando a interferência de chuva.

Cada conjunto de três recipientes, foi interligado a um biodigestor, conforme a Figura 1. Foi denominado de Sistema 1 um conjunto de três recipientes com apenas rejeito, interligados no biodigestor $\mathrm{B} 1$. De Sistema 2 (3 recipientes contendo $60 \%$ de matéria orgânica, $20 \%$ de rejeito e $20 \%$ de reciclável, interligados ao biodigestor $\mathrm{B} 2$ ) e Sistema 3 (3 recipientes com $30 \%$ de matéria orgânica, 35\% de reciclável e 35\% de rejeito, interligados ao biodigestor B3).

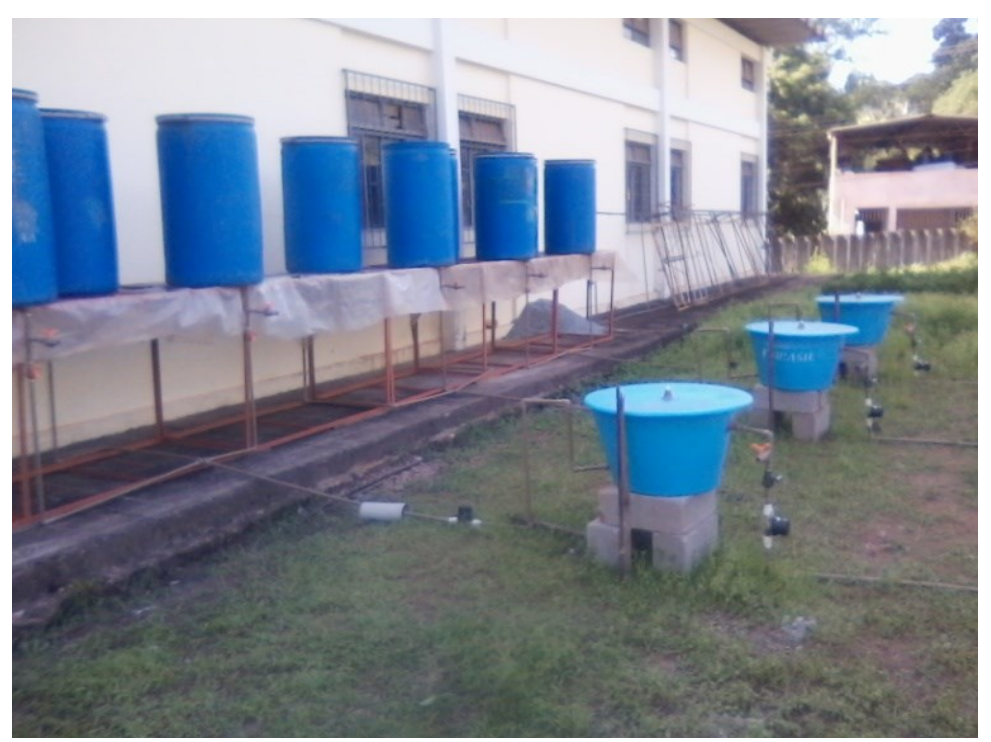

Figura 1 - Esquema dos recipientes interligados aos biodigestores.

Fonte: Marques (2014)

Utilizou-se lodo inoculado proveniente de um reator UASB (Upflow anaerobic sludge blanket digestion) de um matadouro de bovinos, localizado no município de Perdões-MG. Sendo que a partida nos biodigestores foi realizada de acordo com 
metodologia sugerida por Chernicharo (2007). Em cada biodigestor foi colocado aproximadamente 20 litros de lodo, até que o sistema ficasse em equilíbrio.

Os biodigestores foram tampados de modo a vedar a caixa para as reações anaeróbias (Figura 2).

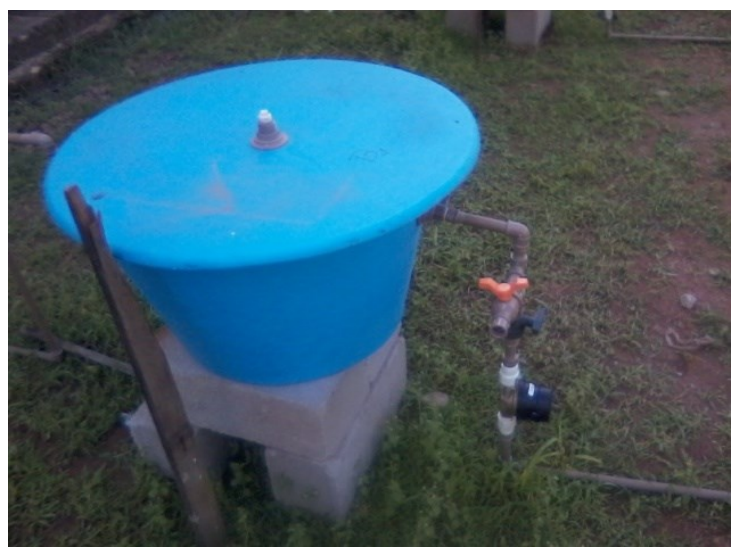

Figura 2. Biodigestor tampado

Fonte: Marques (2014)

A alimentação dos biodigestores foi através da aplicação de água nos resíduos com volume de 4 litros em cada recipiente a cada dois dias, totalizando uma vazão de entrada no biodigestor de 12 litros a cada 2 dias, com um volume útil de 55 litros, totalizando um tempo de detenção hidráulica de 9,2 dias, obtido por meio da equação 1 .

$t_{h}=\frac{V}{Q}$

\section{Em que:}

$\mathrm{t}_{\mathrm{h}}=$ tempo de detenção hidráulica (dia)

$\mathrm{Q}=$ vazão afluente de substrato $\left(\mathrm{m}^{3} \cdot \operatorname{dia}^{-1}\right)$

$\mathrm{V}=$ volume útil do reator $\left(\mathrm{m}^{-3}\right)$

A carga orgânica volumétrica (COV) foi calculada conforme a equação 2 . A COV é utilizada para descrever a quantidade de substrato afluente introduzido por volume de reator em determinado tempo, sendo que esse substrato pode ser dado pela Demanda Química de Oxigênio (DQO), Sólidos Totais (ST) ou Sólidos Totais Voláteis (STV).

$$
C O V=\frac{Q * S}{V}
$$

Em que:

$\mathrm{S}=$ concentração do substrato no afluente $\left(\mathrm{kg} \cdot \mathrm{m}^{-3}\right)$

$\mathrm{Q}=$ vazão afluente de substrato $\left(\mathrm{m}^{3} \cdot \mathrm{dia}^{-1}\right)$

$\mathrm{V}=$ volume útil do reator $\left(\mathrm{m}^{-3}\right)$

Foram realizadas coletas dos afluentes (na entrada dos biodigestores, visando identificar o potencial poluidor) e dos efluentes (na saída dos biodigestores para avaliar a eficiência de remoção de matéria orgânica remanescente). As coletas foram realizadas semanalmente no período da manhã, totalizando 12 amostras/coleta (9 recipientes e 3 biodigestores), sendo o período de monitoramento de 3 meses, perfazendo um total de 10 coletas. Os parâmetros avaliados foram a $\mathrm{DQO}$, sólidos totais, $\mathrm{pH}$ e alcalinidade, seguindo orientações de acordo com Standart of Methods (APHA, 2005).

Para tanto, foi aplicado uma estatística descritiva para a análise dos dados. 
RESULTADOS E DISCUSSÃO

\section{Remoção de matéria orgânica}

Na Tabela 1, estão apresentados os dados relativos à estatística descritiva do parâmetro correspondente à matéria orgânica (DQO) e sólidos totais (ST) dos afluentes e efluentes dos sistemas.

Tabela 1. Estatística descritiva dos valores das concentrações das variáveis de monitoramento.

\begin{tabular}{|c|c|c|c|c|c|c|c|c|c|}
\hline & & \multicolumn{4}{|c|}{ Afluente } & \multicolumn{4}{|c|}{ Efluente } \\
\hline Parâmetros & & Mín. & Média & Máx. & Sd & Mín. & Média & Máx. & Sd \\
\hline \multirow{3}{*}{ DQO $\left(\mathrm{mg} \mathrm{L}^{-1}\right)$} & $\mathrm{S} 1$ & 1252 & 3185 & 6696 & 1735 & 1001 & 3704 & 6434 & 1770 \\
\hline & $\mathrm{S} 2$ & 2504 & 5037 & 9703,8 & 2622 & 1071 & 4680 & 10286 & 3008 \\
\hline & $\mathrm{S} 3$ & 2365,2 & 4695,9 & 9630,1 & 2186,6 & 1106,9 & 3298,2 & 6627,3 & 1856 \\
\hline \multirow{3}{*}{$\mathrm{ST}\left(\mathrm{mg} \mathrm{L^{-1 }}\right)$} & $\mathrm{S} 1$ & 2217 & 6028 & 18600 & 5586 & 2050 & 5370 & 16700 & 4300 \\
\hline & $\mathrm{S} 2$ & 3433 & 9615 & 18380 & 4895 & 3400 & 10115 & 29600 & 9116 \\
\hline & S3 & 2867 & 7946 & 22580 & 6679 & 2050 & 4855 & 13000 & 3587 \\
\hline
\end{tabular}

De acordo com a Tabela 1, observase que a concentração de DQO no afluente do Sistemal variou de 1252 a $6696 \mathrm{mg} \mathrm{L}^{-1}$. Nos Sistemas 2 e 3, as variações de DQO foram de 2504,3 a $9703,8 \mathrm{mg} \mathrm{L}^{-1}$ e de 2365,2 a $9630,1 \mathrm{mg} \mathrm{L}^{-1}$ respectivamente, podendo inferir que quanto maior $\mathrm{o}$ percentual de matéria orgânica depositada nos recipientes, maior a DQO. Para os efluentes, ou seja, após o tratamento com biodigestores, a DQO variou de 1001 a 6434 mg.L $L^{-1}$ no Sistema 1, 1071 a 10286 mg.L $\mathrm{L}^{-1}$ no Sistema 2 e 1107 a 6627 mg.L - $^{-1}$ para o Sistema 3. Observa-se que principalmente em relação aos valores médios que apenas o Sistema 1 não apresentou remoção, ao contrário, um aumento da matéria orgânica, podendo ser explicado pela vazão que possivelmente pode ter promovido o arraste de sólidos, quando comparados aos Sistemas 2 e 3.

A Figura 3 apresenta a evolução temporal e a comparação entre o afluente e o efluente, corroborando com as discussões de acordo com a tabela descritiva. Nota-se na Figura picos na concentração de DQO após o tratamento, que possivelmente foi devido ao arraste de sólidos do lodo. Observa-se que o Sistema 3 obteve o melhor desempenho para os parâmetros analisados.

Para os Sistemas 2 e 3 houve baixa eficiência, obtendo eficiência global de 8,61 e $24,14 \%$ respectivamente, porém não considerado satisfatório de acordo com a legislação.

$\mathrm{Na}$ Figura 2, são apresentadas as tendências das evoluções temporais dos sólidos totais (ST) durante o período experimental. Verificou-se ao longo do 
experimento valores de ST nos afluentes compreendidos entre 2217 a 18600 mg.L - $^{-1}$ para o Sistema 1, enquanto que nos afluentes dos Sistemas 2 e 3 foram de 3433 a $18380 \mathrm{mg} . \mathrm{L}^{-1}$ e 2867 a $22580 \mathrm{mg} . \mathrm{L}^{-1}$ respectivamente. Já no efluente do Sistema 1 essa variação foi de 2050 a $16700 \mathrm{mg} . \mathrm{L}^{-1}$. Para o Sistema 2 essa variação foi de 3400 a $29600 \mathrm{mg} \cdot \mathrm{L}^{-1}$. Para o Sistema 3, foi de 2050 a $13000 \mathrm{mg} \cdot \mathrm{L}^{-1}$.
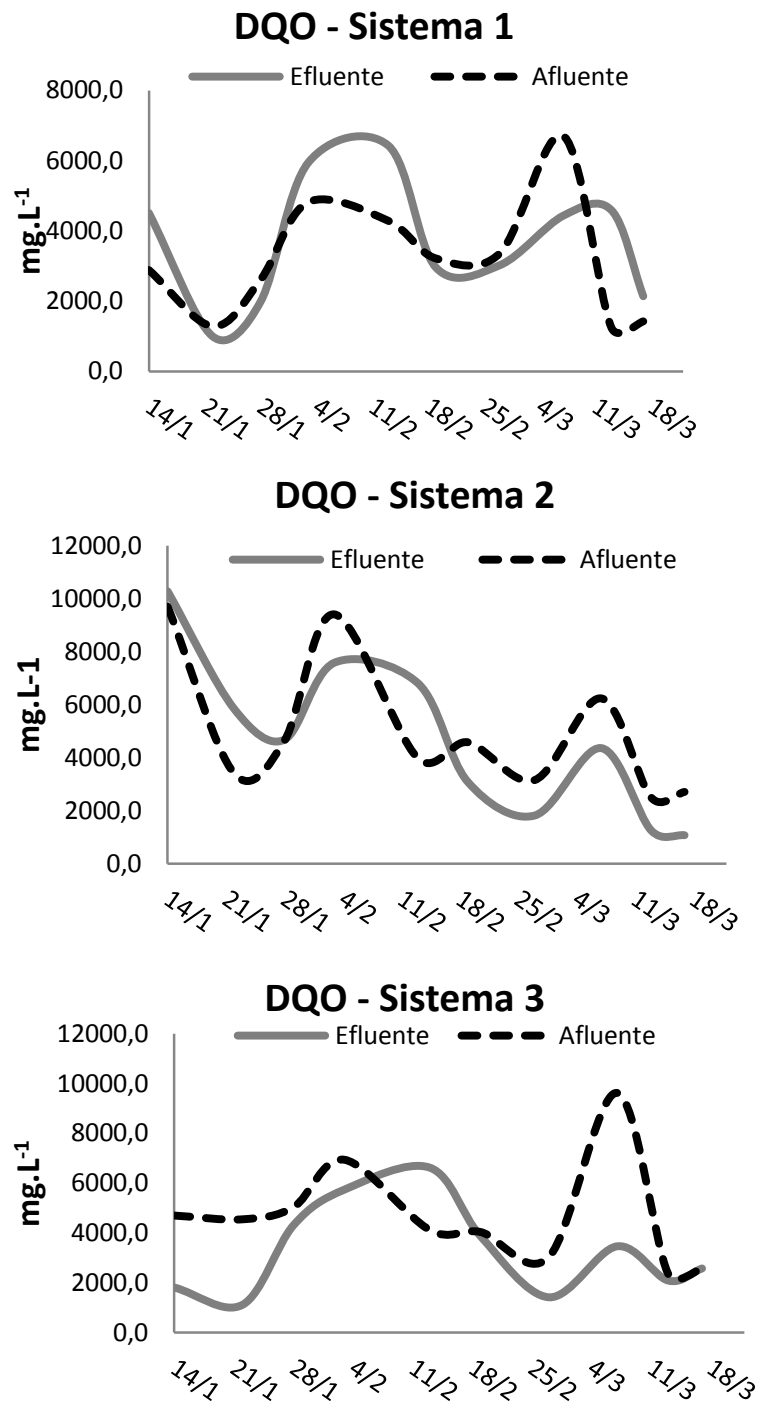

Analisando o tratamento efetuado pelos biodigestores, observa-se uma remoção satisfatória de $\mathrm{ST}$, com exceção no início do tratamento pelo Sistema 2 e em um pequeno período pelo Sistema 1. Para este caso, o biodigestor pode ser considerado um sistema de tratamento eficaz.

As eficiências médias de remoção de ST foram de $-3,68 \%, 5,36 \%$ e $35,09 \%$ para os biodigestores B1, B2 e B3 respectivamente.
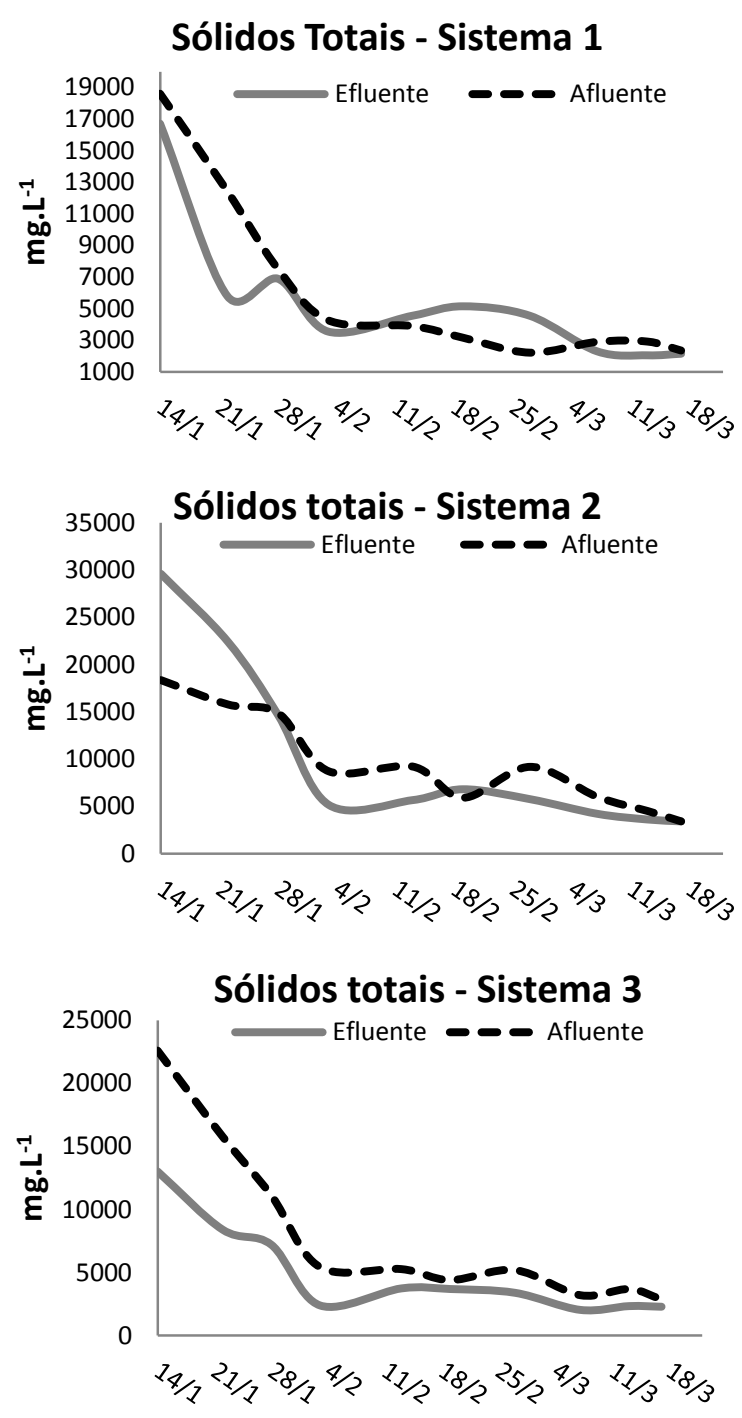

Figura 3. Variações de DQO e sólidos totais do afluente e efluente dos Sistemas 1, 2 e 3 ao longo do período experimental 
Segundo Lettinga e Hulshoff Pol (1991) materiais particulados orgânicos, comprometem o sistema anaeróbio, dependendo de suas características, tais como: biodegradabilidade e/ou taxa de degradação sob as condições operacionais prevalecentes, tamanhos e área superficial do material particulado, afinidade dos microrganismos em atacar o material, densidade dos particulados, isto é, sedimentabilidade e flotabilidade, e tendência do material adsorvido pelo lodo. E ainda, o acréscimo de sólidos no efluente pode indicar irregularidade operacional e provocar o arraste de partículas ou o acúmulo de lodo. Então é indicado um sistema de pós tratamento.

\section{pH, Alcalinidade e Ácidos Voláteis}

A interação entre $\mathrm{pH}$, Ácidos Voláteis totais (AVT) e alcalinidade expressam o equilíbrio de um sistema de digestão anaeróbia, sendo importantes para o controle e a operação adequada dos processos anaeróbios (CHERNICHARO, 2007) indicando que a fermentação ácida não possui predominância sobre a fermentação metanogênica.

Pela Tabela 2 é possível observar que as faixas de valores de $\mathrm{pH}$ do afluente ficaram entre 6,7 e 7,2 no Sistema 1, de 6,3 a 7,3 no afluente do Sistema 2 e de 6,4 a 7,14 no Sistema 3 , enquanto que nos efluentes de 7,1 a 8,2 no Sistema 1, de 7,4 a 7,9 no Sistema 2 e de 6,78 a 8,0 no Sistema 3. Estes valores, com exceção do efluente do Sistema 1 que passou levemente do indicado, estão dentro da faixa de crescimento de microorganismos produtores de metano, com estabilidade na formação de metano (CHERNICHARO, 2007).

Tabela 2. Estatística descritiva dos valores das concentrações das variáveis de monitoramento

\begin{tabular}{cc|cccc|cccc}
\hline \multicolumn{1}{c}{ Afluente } & \multicolumn{5}{c}{ Efluente } \\
\hline & & Mín. & Média & Máx. & Sd & Mín. & Média & Máx. & Sd \\
\hline \multirow{3}{*}{ Sistema } & AH & 6,7 & 6,8 & 7,2 & 0,17 & 7,1 & 7,6 & 8,2 & 0,3 \\
$\mathbf{1}$ & AVT & 2504 & 3656 & 6245 & 1747 & 11000 & 14580 & 27000 & 5163 \\
& COV & & & & & & 0,35 & & \\
\hline & pH & 6,3 & 6,8 & 7,3 & 0,3 & 7,4 & 7,6 & 7,9 & 0,2 \\
Sistema & AT & 11333 & 18533 & 30667 & 5414 & 1000 & 21540 & 49200 & 12377 \\
$\mathbf{2}$ & AVT & 12480 & 22325 & 42560 & 11397 & 9840 & 26712 & 63840 & 19103 \\
& COV & & & & & & 0,55 & & \\
\hline & pH & 6,43 & 6,65 & 7,14 & 0,22 & 6,78 & 7,418 & 8,06 & 0,4 \\
Sistema & AT & 5334 & 13474 & 19600 & 4077 & 8000 & 14260 & 35400 & 7880 \\
3 & AVT & 10480 & 22589 & 37280 & 8300 & 7440 & 12072 & 19200 & 3850 \\
& COV & & & & & & 0,51 & & \\
\hline
\end{tabular}


Potencial Hidrogeniônico $=\mathrm{pH} ;$ Alcalinidade Total $=$ AT Ácidos Voláteis Totais = AVT; Carga Orgânica Volumétrica $=\mathrm{COV}$.

Ainda, de acordo com a Tabela 2 e Figura 4 são apresentadas as concentrações de Alcalinidade Total (AT) e os perfis dos AVT, ao longo do período de monitoramento do efluente do biodigestor.

As concentrações da alcalinidade total variaram de 2504 a $6245 \mathrm{mg} \mathrm{CaCO} 3 . \mathrm{L}^{-}$ 1 para Sistema 1, de 11333 a $30667 \mathrm{mg}$ $\mathrm{CaCO}_{3} \cdot \mathrm{L}^{-1}$ e de 5334 a $19600 \mathrm{mg} \mathrm{CaCO}_{3} \cdot \mathrm{L}^{-}$ ${ }^{1}$ para os Sistemas 2 e 3 respectivamente. Para os efluentes os valores variaram de 11000 a $27000 \mathrm{mg} \mathrm{CaCO}_{3} \cdot \mathrm{L}^{-1}$, de 1000 a $49200 \mathrm{mg} \mathrm{CaCO}{ }_{3} \cdot \mathrm{L}^{-1}$ e de 8000 a $35400 \mathrm{mg}$ $\mathrm{CaCO}_{3} \cdot \mathrm{L}^{-1}$ para os biodigestores Sistemas 1, 2 e 3 respectivamente.

Observa-se que houve um aumento do afluente para o efluente, indicando haver geração de alcalinidade nos biodigestores proporcionando capacidade tampão nos biodigestores, que também foi responsável pelo aumento do $\mathrm{pH}$. Já em relação ao Sistema 3, esse demonstra que os valores do efluente estão estabilizados em relação ao afluente de $30 \%$ de matéria orgânica.

O equilíbrio dos AVT é importante no estudo dos reatores anaeróbios. Altas concentrações de AVT podem afetar o processo bioquímico e, eventualmente, causar distúrbios no processo de digestão anaeróbia, podendo levar o reator até mesmo ao colapso. A geração de grandes concentrações de ácidos graxos voláteis acelera a atuação de bactérias acetogênicas, porém é inibitória aos microrganismos metanogênicos, uma vez que não consomem os ácidos resultantes da acetogênese com a mesma rapidez com que são produzidos.

As concentrações de AVT no afluente, foram de 8800 a $25840 \mathrm{mg}$ HAc. $L^{-1}$ no Sistema 1, de 12480 a 42560 mg HAc. $L^{-1}$ no Sistema 2 e de 10480 a 37280 mg HAc. $L^{-1}$ no Sistema 3. Já nos efluentes

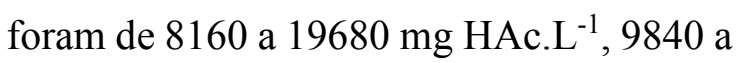
63840 mg HAc.L ${ }^{-1}, 7440$ a 19200 mg HAc. $L^{-1}$ para os Sistemas 1, 2 e 3 respectivamente.

Observou-se uma redução nas concentrações ao passar pelos biodigestores, principalmente em relação ao Sistema 3, mostrando um consumo de AVT pelas bactérias anaeróbias, caracterizando estabilidade dos reatores anaeróbios. Em contrapartida, observou-se um acréscimo nas concentrações em relação ao biodigestor do Sistema 2, sugerindo uma maior atividade hidrolítica e acidogênica .

A carga orgânica volumétrica (COV) aplicada foi de $0,35 \mathrm{~kg}$ DQO $\mathrm{m}^{-3} \mathrm{~d}^{-1}$ para o Sistema $1,0,55 \mathrm{~kg}^{\mathrm{DQO}} \mathrm{m}^{-3} \mathrm{~d}^{-1}$ para o Sistema 2 e de $0,51 \mathrm{~kg}$ DQO $\mathrm{m}^{-3} \mathrm{~d}^{-1}$ para o Sistema 3. De acordo com Reis (2012), para o chorume, valores aceitáveis para um funcionamento de qualidade é de até $0,5 \mathrm{~kg}$ DQO $\mathrm{m}^{-3} \mathrm{~d}^{-1}$. 
A COV teve relação com a quantidade de matéria orgânica colocada nos recipientes. Observa-se que apenas o Sistema 1 se enquadra dentro do ideal, porém o Sistema 3 mesmo apresentando uma maior COV, apresentou um melhor desempenho em relação aos demais parâmetros (DQO, pH, alcalinidade, AVT e ST).
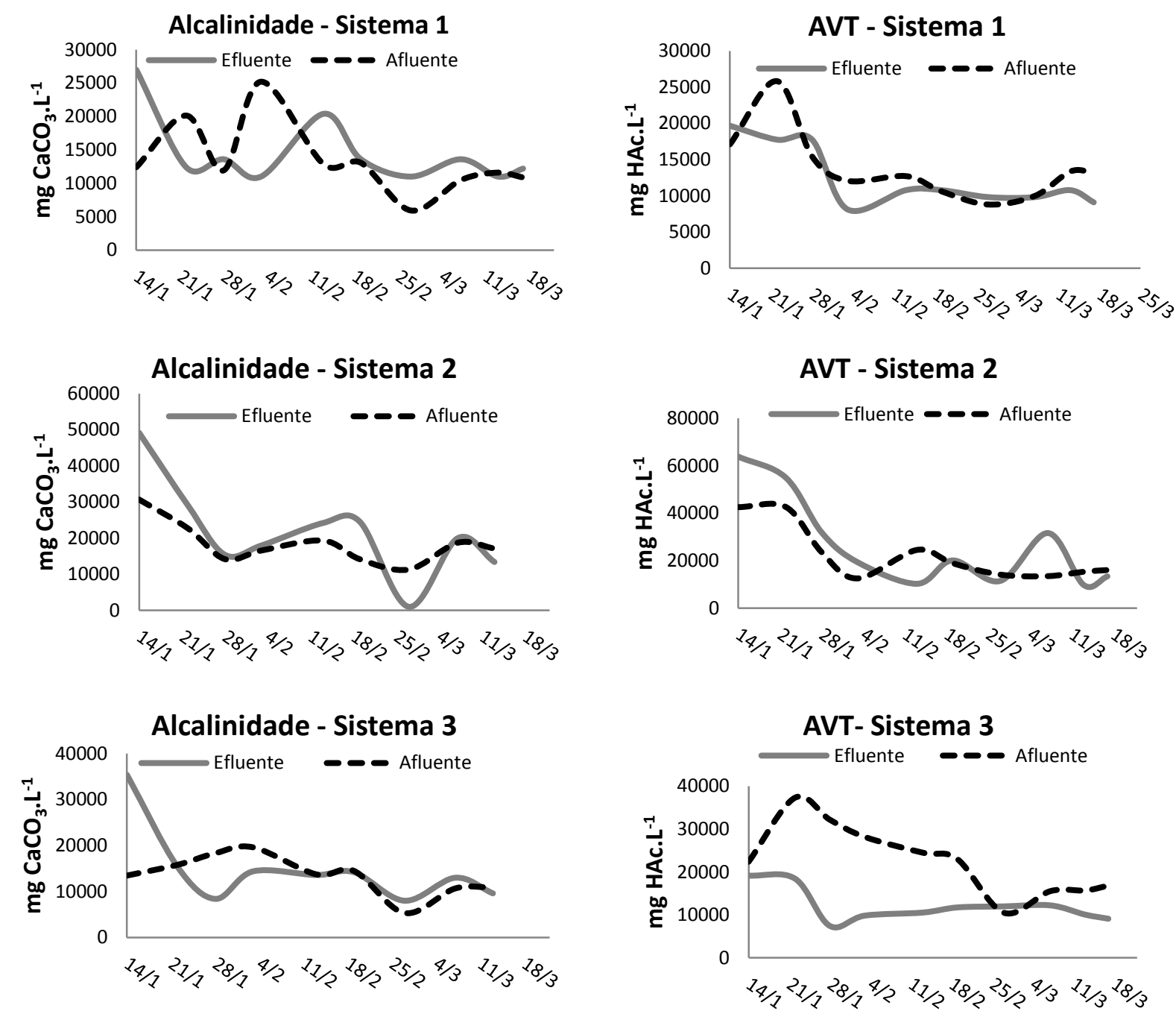

Figura 4 Variações de Alcalinidade e Ácidos Voláteis Totais (AVT) do afluente e efluente dos Sistemas 1, 2 e 3 ao longo do período experimental

\section{CONCLUSÕES}

O Sistema 3 foi o que apresentou melhor desempenho em relação aos parâmetros estudados, muito possivelmente em relação ao teor de matéria orgânica ideal, corroborando com a legislação que preconiza o aterramento de apenas $30 \%$ de matéria orgânica para aterro sanitário de pequeno porte.

Os níveis de remoção de matéria orgânica também não foram satisfatórios 
conferindo uma maior eficiência para o Sistema 3 que foi apenas de 24\%. Esses resultados indicam que o efluente possui características inadequadas para $\mathrm{o}$ lançamento e/ao reuso, sendo necessária a adição de uma etapa de pós-tratamento para adequação do mesmo.

\section{REFERÊNCIAS}

APHA standard methods: for examination of water and wastewater. 21 th ed.

Baltimore: APHA, AWWA, WPCP, 2005.

BARCELOS, B. R., Avaliação de diferentes inóculos na digestão anaeróbia da fração orgânica de resíduos sólidos domésticos. 2009.75 f. Dissertação (Mestrado em Tecnologia Ambiental e Recursos Hídricos)Universidade de Brasília, Brasília, 2009.

BRASIL. Ministério da Agricultura e Reforma Agrária. Secretaria Nacional de Irrigação. Departamento Nacional de Meteorologia. Normais Climatológicas (1961-1990). Brasília, 1992, 84p.

BRASIL. Lei $\mathrm{n}^{\circ} 12.305$, de 2 de agosto de 2010. Institui a Política Nacional de Resíduos Sólidos; altera a Lei no 9.605, de 12 de fevereiro de 1998; e dá outras providências. Disponível em: < http://www.mma.gov.br/port/conama/legia bre. $\mathrm{cfm}$ ?codlegi $=636>$. Acesso em: 21 jan. 2011.

BOSCOV, M. E. G., ABREU, R. C. de. Aterros Sanitários. In: Previsão de desempenho - comportamento real aterros sanitários, taludes, túneis, fundações, aterros sobre solos moles, pp. 7-44, São Paulo: ABMS/NRSP, 2000.

CHERNICHARO, C. A. L. Reatores Anaeróbios (Principíos do trtamento bioógico d águas residuárias). 2 ed. Belo Horizonte: Departamento de Engenharia Sanitária e ambiental - UFMG. 380p.

DIXON, N., JONES, D. R. V. (2005) Engineering properties of municipal solid waste. Geotextiles and geomembranes. vol. $25, n^{\circ} .3$, pp. 205-212.

DURMUSOGLU, E., SANCHEZ, I. M., CORAPCIOGLU, M. Y. (2006).

Permeability and compression characteristics of municipal solid waste samples. Journal Environmental Geology. vol. 50, nº 6, pp. 773-786.

FRANCO, C. S., Caracterização gravimétrica dos resíduos sólidos domiciliares e percepção dos hábitos no descarte no Sul de Minas Gerais. Lavras: UFLA, 2012, 157p.

GAO, W.J.J.; LIN, H.J.; LEUNG, K.T. et al. Influence of elevated $\mathrm{pH}$ shocks on the performance of a submerged anaerobic membrane bioreactor. Process

Biochemistry, Oxford, v.45, n.8, p.12791287, 2010.

KUNZ, A. Dimensionamento e manejo de biodigestores. 2010. Embrapa Suínos e Aves, Concórdia/SC. Disponível em: $<$ http://www.cnpsa.embrapa.br $>$.

LETTINGA, G., HULSHOFF POL, L. M. (1991). Uasb-process design for various types of wastewaters., Water Science Tech., 24, 87-107.

\section{MARQUES, R.F.P.V., Tratamento} biológico de percolados de resíduos sólidos urbanos pela associação entre reator anaeróbio de baixa carga e wetlands. Tese. UFLA, 2014.

RASTOGI, G.; RANADE, D.R.; YEOLE, T.Y. et al. Investigation of methanogen population structure in biogas reactor by molecular characterization of methyl-coenzyme $M$ reductase A (mcrA) 
genes. Bioresource Technology, Oxford, v.99, n.13, p.5317-5326, 2008.

REIS, A. S., Tratamento de resíduos sólidos orgânicos em biodigestor anaeróbio. Recife: $\mathrm{O}$ autor, 2012.

YADVIKA; SANTOSH;

SREEKRISHNAN, T.R. et al.

Enhancement of biogas production from solid substrates using different techniques-a review. Bioresource Technology,

Oxford, v.95, n.1, p.1-10, 2004. 